\title{
The role of emotions in the control-resistance dyad
}

\author{
Henrique Duarte $^{\mathrm{a}, *}$, Ofelia A. Palermo ${ }^{\mathrm{b}}$, Patricia Arriaga ${ }^{\mathrm{c}}$ \\ a BRU-IUL, Instituto Universitário de Lisboa (ISCTE-IUL), ISCTE- IUL Cacifo 175, Av das Forças Armadas, 1649-026 Lisboa, Portugal \\ ${ }^{\mathrm{b}}$ Nottingham Business School, Nottingham Trent University, Burton Street, NG14BU Nottingham, United Kingdom \\ c CIS-IUL, Instituto Universitário de Lisboa (ISCTE-IUL), ISCTE- IUL Cacifo 336A, Av das Forças Armadas, 1649-026 Lisboa, Portugal
}

\section{A R T I C L E I N F O}

\section{Keywords:}

Socio-ideological controls

Emotions

Resistance

Organizational citizenship behaviour

Counterproductive work behaviours

Post-bureaucracy

\begin{abstract}
A B S T R A C T
This paper investigates the implications of perceived Socio-Ideological Organizational Controls (SIOC) dimensions on actors' lived experiences in the workplace. We explored whether emotions mediated the dyad controlresistance. Data was collected from 385 participants, via a self-administered questionnaire framed as part of a cross-sectional survey design. Our findings suggest that SIOC dimension related to the promotion of values is an important predictor of experiencing higher positive emotions and lower negative emotions at work. The positive emotions, in turn, predict higher organisational citizenship levels and lower resistance behaviours. Based on these findings, we discuss the role and effectiveness of organisational controls inspired by discursive practices.
\end{abstract}

\section{Introduction}

In management literature, rationalist and normative theories look at the issue of control and attempt to explain how and why organisations adopt certain forms of control (Barley \& Kunda, 1992) rather than others. Among the various types of control mechanisms illustrated in literature, we are particularly interested in those that aim at influencing individuals' behaviours. Rational explanations (e.g. the promotion of employees' self-interest) or normative ones (e.g. organisations' efforts to regulate thoughts and emotions) tend to underpin the debate on what guides organisations in the choice of their preferred control mechanisms. In spite of the nature of the explanation, the aim of control is often that of fostering behaviours that favour a predictable and effective organisational climate (Etzioni, 1965; Gabriel, 1999; Malmi \& Brown, 2008; Raelin, 2011; Styhre, 2008), and that comply with organizational expectations (Collinson, 1994). A dichotomy between bureaucratic mechanisms aimed at enacting desired cognitions and motivations, and cultural and emotional regulation stresses the fact that organisations use different means to obtain actors' compliance, or to exert power and pressure over employees (Fineman, 2001; Gabriel, 1999). This suggests that the notion of control cannot be dissociated from the notion of resistance to power (Gabriel, 1999), and from the possible cognitions and emotions that can be tied to such resistance.

In our study, we aim to contribute to this debate, paying particular attention to the role of emotions per se, and to the extent to which ideological controls can be associated with the emotions individuals' feel in the workplace. To do so, our first goal is to understand if ideological controls are associated with individual performance. In addition to bureaucratic ones, new forms of control relying on culture, promotion of beliefs, and change of procedures and structures (Fleming, 2013; Gabriel, 1999; Gabriel, Geiger, \& Letiche, 2011) align employees' behaviours, and broadly create organisationally productive environments. Some examples of those types of controls are the Socio-Ideological Organizational Controls (SIOC), as proposed by Alvesson and Karreman (2004). Their aim is to influence the mind-sets of employees, who would eventually internalize the desired values and norms. The difference between SIOC and the more traditional forms of control is that the latter tend to rely on bureaucratic procedures that require a direct type of surveillance over actors (Ouchi \& Maguire, 1975; Snell \& Youndt, 1995). SIOC, instead, are tied to post bureaucratic management ideas framed for overcoming the limitations of bureaucracy, facilitating adaptation, potentiating innovation (McKenna, Garcia Lorenzo, \& Bridgman, 2010), reducing resistance to control, and reducing counterproductive work behaviours (CWB; Erkama, 2010; Fleming, 2013; Dischner, 2015). Based on a functionalist perspective, in this study we illustrate the links between perceived SIOC, productive behaviours, and possible resistant behaviours. We add new evidence for identifying other possible antecedents of in-role and extra-role behaviours like organizational citizenship behaviours (OCB). Research on organizational performance, OCB, and CWB (Berry, Ones \& Sackett, 2007; Combs, Liu, Hall, \& Ketchen, 2006; Dalal, 2005; Jiang, Lepak, Hu \& Baer, 2012) tends to adopt a more bureaucratic perspective, pivoting around the use of human resource policies, leadership support, justice, and reciprocity to the organization.

In our overall attempt to understand the relations of ideological controls with expected behaviours but also the possible reactions to its

\footnotetext{
* Corresponding author.

E-mail addresses: hmcd@iscte.pt (H. Duarte), ofelia.palermo@ntu.ac.uk (O.A. Palermo), patricia.arriaga@iscte.pt (P. Arriaga).
} 
existence, our second goal is to expand the debate about the processes that explain the possible reduction of resistance to perceived ideological controls. As Jensen and Raver (2012) argued, the effects of SIOC on employees' cooperation and/or resistance behaviours are still not clear because of their subtleness and ambiguity (Erkama, 2010; Fleming, 2013; Gabriel, 1999). At a first glance, organizations tend to reduce the potential for resistance (El-Sawad \& Korczynski, 2007), by shifting from detailed rules guiding daily work, to forms of control that "rely on enculturation, identification with company objectives, and processes of subjectification" (Styhre, 2008, p. 640). Some scholars also argue that because employees actually do not perceive the new forms of control, their potential to resist is eradicated from the workplace (Casey, 1996, 1999; Sewell \& Wilkinson, 1992).

Through the introduction of SIOC, individuals are colonized from the inside, rather than from above or from the outside, and, therefore, they might comply with organizational demands by adopting "desirable" behaviours, or they might allow a mutual adjustment due to the shared sense making that replaces the asymmetrical processes associated with bureaucratic controls (Raelin, 2011). These considerations emerging from the literature highlight the subjective aspects associated with employees' lived experience. Employees might perceive the values portrayed by the organization, they might comply with the prevailing discourses, they might adhere to rituals, and comply with expectations (Collinson, 1994), but the ways such dynamics occur still offers scope for further exploration, especially in terms of actors' emotional responses. This micro perspective we adopt in our study (Wright \& Boswell, 2002; Krausert, 2017) allows us to understand the extent to which employees' perception of controls can be associated with less compliance with normative expectations and specific resistance behaviours.

Finally, the third goal we aim to achieve by focusing on emotions is to understand the extent to which they are associated with ideological forms of control (Fineman, 1993, 2001; Fineman \& Sturdy, 1999; Elfenbein, 2007), and the reporting of productive and resistance behaviours. According to these authors, emotions are deeply associated with the aims and processes of control in organizations. Emotions can be considered instrumental to shaping organizational interests, and to some extent can even be an object of exchange - e.g. commoditized emotions (Lindebaum, 2012). Thus, a key role of our study is to understand the role that emotions play in the control-resistance dyad. Although emotions are consistently reported as antecedents of OCB and CWB (Dalal, 2005, Kaplan, Bradley, Luchman \& Haynes, 2009), few studies shed light on the link between organizational controls and the emergence (or co-occurrence) of affective states. This occurs in spite of the strong theorization about emotions and their roles in organizations (Ashforth \& Humphrey, 1995; Elfenbein, 2007; Fineman, 1993, 2001).

Studies that attempt to explore the links between ideological controls and emotions tend to draw on interpretivist epistemologies (e.g. Alvesson \& Karreman, 2004; Erkama, 2010; Fineman \& Sturdy, 1999). By taking a different epistemological stance, we add new evidence to how positive and negative emotions can account for the relationship between perceived SIOC and self-reported behaviours. Our three goals rely on the subjectification of individuals, the perceptions emerging from the SIOC affecting them, and the emotions they report. We refer to the SIOC based on Gabriel's (1999) work, which we will detail further on in this paper. We also refer to the individual level of analysis, which allows us to capture employees' lived experience in their work setting. To do so we focus on what they think about their organization, what emotions they associate to specific events, and what type of behaviours they say they perform (in-role, extra-role, and resistant behaviours). Specifically, we consider a comparison between two types of relationships: the one between employees' emotions and the perceptions of organisation's discourses; and the one between employees' emotions and the perceptions of organizations' adoption of practices that affect the tangible side of control (e.g. modifying surveillance technologies, implementing structural changes).

\subsection{Socio-ideological organizational controls (SIOC) and implications on productive and resistance behaviours}

The key aspect that differentiates SIOC from the traditional controls is that SIOC attempt to generate a particular form of organizational experience for employees, based on the micro-processes of interpretation and meanings that can become widely understood and shared by organizational actors (Alvesson \& Karreman, 2004). Although the literature suggests that SIOC have instrumental aspects similar to traditional controls (Ouchi \& Maguire, 1975; Snell \& Youndt, 1995; Yu \& Ming, 2008), traditional controls are particularly focused on Human Resource policies and exert direct control over performance as a way of aligning individuals with the interests of the organization (Wright \& Boswell, 2002). SIOC, instead, aim at gaining employees' support; they do so by providing individuals with a set of discourses that can influence their self-guidance and implement new organizational procedures and arrangements.

A specific discussion about SIOC emerges from Gabriel's (1999) work. He distinguishes these types of controls from traditional ones in terms of how the actual control is implemented. Traditional controls influence, constrain, and shape individuals from the outside, while SIOC use language and discourse to affect individuals' thoughts, feelings, and behaviours, ultimately influencing their identities. In his reflections, Gabriel emphasizes how these controls fall into the following four interrelated categories: (1) structural changes - associated with flatter hierarchies, flexible working practices, continuous benchmarking, and measurement; (2) changes in manufacturing technologies - associated with lean production but also applicable to service organizations if interpreted as changes in the way the services are delivered; (3) changes in surveillance technologies - associated with systems that can make single individuals accountable for operational failures; and (4) concerted attempts by management to promote new sets of values, attitudes, and beliefs favouring quality, service excellence, teamwork and, last but not least, loyalty. This last category is closely linked with the cultural aspects of control. It tends to reflect those elements that are used by management for building strong corporate cultures, or for giving rise to discourses that generate compliance with organizational expectations (Casey, 1996; Fleming, 2013; Willmott, 1993). In terms of results, they help to control individuals through changes in the arrangements of work. However, in terms of ways of acting and attributing meaning to work itself, the first three categories are linked with a set of non-discursive practices while the last one is directly linked with a more discursive perspective implemented by management. The last directly promotes meanings and influences actors' ways of thinking, feeling, and interacting with other individuals.

Literature offers contrasting explanations on the effects of SIOC: the cultural perspective, the post-structuralist perspective, and the support perspective. The cultural perspective identifies the effectiveness of SIOC in their ability to foster the internalization of values and which, in turn, guides employees' actions (Giorgi, Lockwood \& Glynn, 2015; Harris \& Ogbonna, 2011; Kunda, 2006; Malmi \& Brown, 2008). The cultural perspective suggests that organizations can create strong cultures by inculcating values, spreading beliefs, and regulating emotions (Kunda, 2006; Malmi \& Brown, 2008; Peters \& Waterman, 1982). This affects employees' performance and supports that of the organization. The criticism to this cultural perspective is that it might lead to overlooking the existence of organizational subcultures as well as the different ways individuals make sense of the values and beliefs portrayed by the organization (Malmi \& Brown, 2008). Drawing on this criticism, one identifies the need for understanding how individuals perceive discourses and values and participate in the socialization practices as agents of the behaviours desired by the organization.

The post-structuralist perspective suggests that the effectiveness of SIOC relies on the subjectification of individuals, and on the changes in their identity (Gabriel, 1999). Thus, the promotion of beliefs and the organizational process may lead individuals to redefine themselves 
accordingly, behaving as expected by the organization, as part of their own identities. The support perspective suggests that by "equipping" individuals with new meanings, the perception of SIOC may create feelings of support and trust in the organization and, consequently, entail behaviours that might be more productive, such as those expressing organizational citizenship (Jensen \& Raver, 2012; Vosselman \& van der Meer-Kooistra, 2006). Sewell and Wilkinson (1992) argue that SIOC make surveillance practices acceptable or even invisible leading to greater effort and less resistance from employees. Drawing on the cultural perspective, the instrumentality, the trust aspects, and the possible effects on identity associated with SIOC, we expect employees' greater perception of SIOC to be positively related with behaviours that are productive for the organization (Hypothesis 1).

We acknowledge the on-going debate on whether or not new controls can give rise to employees' resistance (Erkama, 2010, Fleming, 2013) as well as the complexity of the relationship between bureaucratic and post-bureaucratic management strategies, and counterproductive work behaviours (Dischner, 2015). Studies in this field (e.g., Raelin, 2011) have questioned the extent to which SIOC might affect the nature of managers' roles - which would shift from that of "controllers" to that of "emancipated influencers of individuals' self-identity". If this is the case, managers' efforts are focused toward reducing the space organizational resistance might carve out in the construction of employees' self-identities. From a different standpoint, Jensen and Raver (2012) argue that both the development of a sense of trust for the organization and the emergence of resistance behaviours are influenced by the interplay between individuals' self-management opportunities and their perception of being under surveillance. These two features are seen as being responsible for tipping the balance in favour of, respectively, greater trust in the organization and its initiatives, or resistance against it. Other scholars (e.g. Casey 1996, 1999; Sewell \& Wilkinson, 1992) suggest, instead, that the forms of control relying on socialization, enculturation, and identification with the organisation's objectives might act as a form of employees' internal "guidance handbook". By means of this, their identities synchronize with organizational discourses and practice. Such synchronization increases the likelihood of neutralizing resistance.

There are those who take a completely different stance (Erkama, 2010; Gabriel, 1999) arguing that SIOC neither reduce nor eliminate actors' dissent, retaliation, recalcitrance, or resistance; rather, they generate different forms of resistance. While the traditional resistance behaviours relate to employees' overt practices in opposition to management's initiatives (e.g. strike actions, unionism, picketing, and working-to-the rule), new forms of resistance take the shape of discourses, organizational counterproductive behaviours, and retaliatory behaviours that are more pervasive and difficult to manage. Some examples include sabotage, whistle blowing, ritualism, bloody-mindedness, legal recourse, pilfering, output restriction, counter-ideologies, and refusal of discretion (Jermier, Knights \& Nord, 1994; Lawrence \& Robinson, 2007; Skarlicki \& Folger, 1997). Theorizing new forms of resistance is a way to reject the idea that in the context of SIOC, actors' recalcitrance has disappeared (e.g. neutralization of the traditional forms as strike; Beynon, 1975; Fleming \& Sewell, 2002). Overall, we find little agreement in the literature on the interpretation of the relationship between SIOC and resistance. Intrigued by this debate, the second aspect we set out to analyse is whether SIOC offer scope for employees' resistance. In this respect, we argue that individuals' perception of SIOC, supported by the promotion of values and the possible neutralization of dissent, is negatively related to the emergence of resistance behaviours against the organization (Hypothesis 2).

\subsection{The role of emotions on productive and resistant organizational behaviours}

The key debate that emerges from the literature we have examined so far has focused on whether or not SIOC generate productive or resistant behaviours. However, according to Fineman (1993, 2001), Fineman and Sturdy (1999) there can be an intermediate level between control and the emergence of resistance. This intermediate level, or mediator, is represented by emotions.

Drawing on the enactment perspective - which suggests that senior managers have to create and maintain shared meanings for guaranteeing coordinated behaviours in the workplace - Ashforth and Humphrey (1995) argue that managers' success in generating such coordination depends on emotions. Managers can use discourses, symbols, values, attitudes and beliefs for fostering and catalyzing positive emotions. The extent to which they can orchestrate emotions has not been specifically considered in connection with SIOC. However, the promotion of particular values, or the introduction of multiple changes to organizational structures, surveillance, or manufacturing technologies, tend to affect the way employees socialize and develop expectations toward behaviours, attitudes, and emotions. They are influenced by informal practices, for example gradual socialization and performance of organizational rituals (Stearns \& Stearns, 1986). Fineman (2001) points out that the promotion of different emotional rules may lead to fewer organizational efforts to implement direct control and surveillance. Influencing people's thinking and feelings facilitates the occurrence of desirable actions. For instance, a manager's "dramatic" speech can have the power to produce individual and collective actions aligned with the company's goals if it creates favourable emotional reactions toward those goals. Expecting actors to match challenging job descriptions, or achieve demanding goals driven by traditional controls - for example, performance appraisal mechanisms - may not occur without generating emotions capable of winning their involvement. Emotional involvement enables changes to be embraced by organizational actors, and therefore to be implemented; as Fineman suggests, emotions "underpin the essence of control" (Fineman, 2001, p. 234). SIOC are likely to generate stronger emotions than those generated by traditional controls.

Experiencing emotions involves subjective feelings (e.g., happiness, fear, anger), neurophysiological responses (e.g., heart rate), motor expressions (e.g., body movements, facial expressions) and behavioural tendencies expressing action readiness (e.g., approach, avoidance). All of these aspects prepare the individual to deal with the environment (e.g., Frijda \& Scherer, 2009). Emotions trigger action trends that might affect both productive and counterproductive behaviours. This seems to be an aspect worth exploring for explaining the control-resistance dyad.

In literature, the affective events theory (AET) highlights the key role of employees' emotions. It asserts that work events function as affective events by influencing actors' feelings that directly or indirectly elicit certain behaviours (Weiss \& Cropanzano, 1996). Some behaviours (e.g. affect-driven ones) are more susceptible to affective states, like moods. While positive affects emerge as being greater predictors of job performance due to their mediating role as autonomous motivators, negative affects draw on externally controlled motivation or amotivational states and reduce performance (Gillet, Vallerand, Lafrenière, \& Bureau, 2013). Behavioural Inhibition System Sensitivity (Koy \& Yeo, 2008) and Resource Allocation Theory (Kanfer \& Ackerman, 1989) focus on how negative affects reduce attentional resources available for performance, leading to emotional exhaustion, and reduction of job satisfaction, organisational commitment, and personal accomplishment (Thoresen, Kaplan, Barsky, Warren \& Chermont, 2003).

Cognition paths like job satisfaction, instead elicit other behaviours, such as judgment-driven ones. Building on the above assumptions, several authors have claimed that citizenship behaviours (e.g., Ilies, Scott, \& Judge, 2006; Spector \& Fox, 2002; Williams \& Shiaw, 1999) and counterproductive behaviours, such as retaliation or resistance (Schoefer \& Diamantopoulos, 2008; Spector \& Fox, 2002) are affectdriven. In particular, resistance has been associated with emotional states generated by organisational settings. Lawrence and Robinson (2007), for example, lead the way in this field by arguing that resistance can emerge from negative emotions, such as frustration. In their view, 
emotions of this kind can reduce individuals' perceptions of autonomy while performing their jobs. Consequently, feelings of injustice arise and resistance may occur. Spector and Fox (2002) suggest that while counterproductive work behaviours can be triggered by negative emotions - resulting from the attribution of a threatening connotation to management decisions - organisational citizenship behaviours (OCB) are usually elicited by positive emotions, because actors want to preserve and increase their positive affective state.

Fredrickson's (1998, 2001); broaden-and-build theory of positive emotions, explains that positive emotions tend to trigger upward spirals by broadening individuals' attention (e.g. openness to information), cognition (e.g. exploration of new ideas, flexibility, processing of relevant information), and behavioural repertoires (e.g. playfulness, active effort for achieving the goals, efficiency). These contrast with many negative emotions that usually reduce individuals' attention encouraging negative trends (e.g. fight/fight responses). Experiencing affective and attitudinal states in the workplace consistently relates to organisational citizenship behaviours that affect both individuals (OCBI) and the organization as a whole (OCBO) (Ilies et al., 2006). Lyubomirsky, King and Diener (2005) argue that both dispositional happiness and experiencing positive affect predict successful outcomes at work increasing OCB. On the contrary, a lack of happiness can affect job burnout, and generate several counter-productive behaviours, for example withdrawal, organizational retaliation, and conflict amongst colleagues. High emotional strain (e.g. harmful and maladaptive negative emotional responses toward stressors) relates to OCB performance, although this relationship is stronger for OCBO than for OCBI (Chang, Johnson, \& Yang, 2007). Kaplan, Bradley, Luchman and Haynes (2009) suggest that negative emotions are negatively related to several measures of task performance and OCB. Research has produced interesting insights on the relationships between emotions and OCB, however there is still scope for exploring the two types of organisational citizenship behaviours, OCBO and OCBI, more in depth.

The role of employees' emotional states on both productive and counter-productive work behaviours is important. SIOC are environmental events that can elicit particular emotions in employees. Understanding employees' emotions can shed light on how specific control mechanisms unfold, beyond their mechanistic nature of controls.

Little empirical evidence emerges on the mediational role that emotions have in explaining the emergence of both resistance and productive behaviours as responses to control. This gap persists in spite of Collinson's (1994), and Fineman and Sturdy's (1999) call for a greater focus on emotions. In their work, they show how emotions can act as triggers of active and passive resistance, and as a key for understanding resistance per se. To address this gap, we examine whether employees' affective states mediate the relationship between the perception of SIOC and the productive and resistance behaviours. In addition, we look at how employees experience SIOC, given that the way an individual cognitively appraises each SIOC may relate to distinct emotions. In Lazarus's (1982) appraisal theory suggests that individuals' appraisal of a specific situation affects their affective states in different ways. Because positive emotions are tied to a wide range of important positive outcomes (cf. Lyubomirsky et al., 2005), we expect that the relationship between the perception of SIOC and behaviours will be mediated by the emotions actors experience in the workplace. Thus, we expect both the positive relationship between the perception of SIOC and productive behaviours, and the negative relationship with resistance behaviours to be positively mediated by positive emotions (Hypothesis 3 ), and negatively mediated by negative emotions (Hypothesis 4).

In summary, in our study first we look at what SIOC dimensions perceived by employees and are associated with productive, and resistant behaviours. Then, we look at the extent to which emotions can mediate the relationships between perceived SIOC and employees' productive and resistant organisational behaviours (see Fig. 1). To evaluate the micro processes that relate the perception of SIOC, emotions, and behaviours, we use the individual level of analysis. This level has been used effectively in similar studies (eg. Alfes, Truss, Soane, Rees and Gatenby, 2013; Kehoe \& Wright, 2013) because it allows a better understanding of internal processes (Krausert, 2017; Liao, Tya, Lepak and Hong, 2009). Accordingly, our study unfolds in three steps. First, we evaluate which SIOC dimension predicts positive and/or negative emotions; second, we evaluate SIOC associations to in-role, extra-role, and resistance behaviours; and third, we consider the role of emotions as possible mediators between SIOC and organizational behaviours. We conducted linear regressions using only the statistically significant predictors of our criterion variables in order to test for mediation. We tested the indirect effects through both bootstrapping and normal theory approaches.

\section{Method}

\subsection{Participants}

We selected companies based on a convenience sampling method according to those that showed interest in participating in the study. Within companies, participants answered anonymously to the link that was sent randomly for their emails by their companies. The sample included employees with different roles and working in different sectors of activity. Three hundred and thirty-four participants (63.8\% female) formed our sample $\left(M_{\text {age }}=37 ; S D_{\text {age }}=9.29\right)$. The average tenure age was of 8.9 years $(S D=8.20)$ and the working sectors were heterogeneous (industry $18.9 \%$, retail and distribution $8.2 \%$, I.T. $8.5 \%$, civil service $5.5 \%$, other services such as financial, advertising, consultancy were $52.1 \%)$. The size of the organizations also varied $(9.9 \%<10$ people; $24.9 \%$ between 10 and 50 people; $13.2 \%$ between 51 and 100; $18.0 \%$ between 101 and 250 people; $15.9 \%$ between 251 and 500 people; $18.3 \%>500$ people), as well as the jobs they carried out, and their organizational roles in the hierarchy $(21.6 \%$ managers, $42.0 \%$ professional/scientific jobs; $28.5 \%$ qualified/mid-level professionals, $7.8 \%$ other jobs).

\subsection{Research design}

We framed our research within a cross-sectional survey design and, as mentioned, we referred to the individual level of analysis. Similar extant studies (e.g. Tanghe, Wisse, \& van der Flier, 2010; Van Woerkom \& Meyers, 2015) adopted a cross-sectional design, as it is effective in gaining individuals' perceptions and self-reported measures of emotions and behaviours. We used a self-completion questionnaire for collecting data via e-mail. An email was sent to participants with the Internet address where they could find the survey and we guaranteed full anonymity and confidentiality. We provided participants with a small debriefing text and thanked them once data had been collected. For framing our questionnaire we drew on Podsakoff, MacKenzie and Podsakoff's (2012) contributions. In order to reduce the common method bias, we used different measurement scales (as we indicated above) and when different dimensions of the same construct emerged, we separated the order of the items so that the latter were not close to other items of the same dimension. Additionally, to detect the possibility of a common method variance, we first followed the Harman one factor solution, using an exploratory factor analysis (Podsakoff, MacKenzie, Lee, \& Podsakoff, 2003). The first factor explained only $14 \%$ of the variance (KMO $=0.78$ ), which is far from the critical value of $50 \%$. Then, to be confident about the response style of participants, we conducted two new exploratory factor analyses but with two or three items linked to the different dimensions. This allowed us to evaluate the possibility of having latent variables constructs with items related to different variables. In both analyses the rotated solutions distinguished the theoretical dimensions $\left(\mathrm{KMO}_{1}=0.75\right.$ and $\mathrm{KMO}_{2}=0.73$ ). This allowed us to exclude, with some degree of 


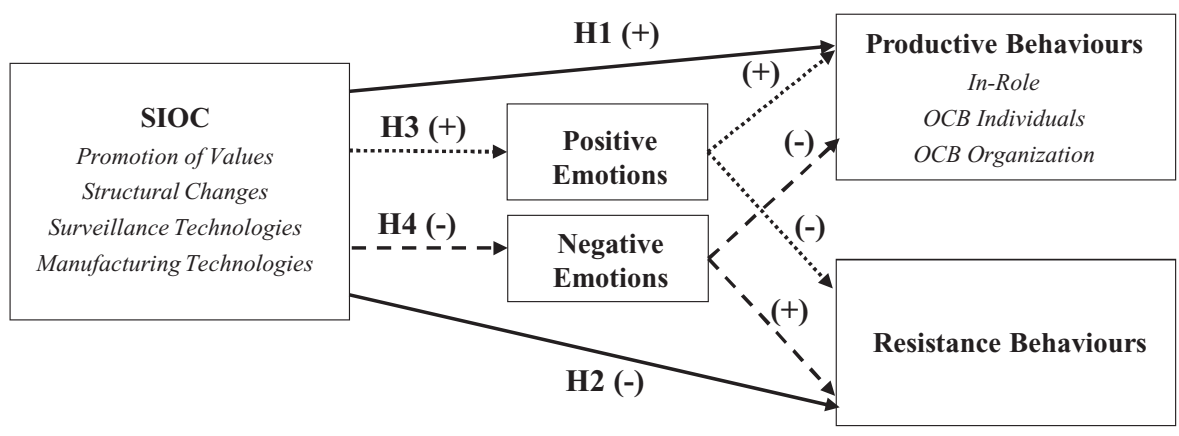

Fig. 1. Expected Relationships Between Perceived SocioIdeological Organizational Controls (SIOC), Emotions and Behaviours. confidence, the existence of halo effects on participants' reponses and the bias of common method variance.

Before testing our hypotheses, we evaluated the psychometric qualities of the scales used in this study through two confirmatory factor analyses. Based on the results, we eliminated items with lower loadings to allow a satisfactory measurement of the variables. In addition, we conducted two confirmatory factorial analysis to look for the multidimensionality of all the scales we used. The results indicated that scales presented reasonable fit to the data. In the first confirmatory analysis we included the four independent variables and the two mediator variables $\left(\chi^{2(260)}=649.483, \mathrm{p}<0.01, \chi^{2} / \mathrm{df}=2.498\right.$, $\mathrm{CFI}=0.902, \mathrm{IFI}=0.903$, RMSEA $=0.067, \mathrm{LO}=0.061, \mathrm{HI}=0.074)$; in the second analysis, we included the four dependent variables $\left(\chi^{2(260)}=649.483, \quad \mathrm{p}<0.01, \quad \chi^{2} / \mathrm{df}=2.498, \quad \mathrm{CFI}=0.902\right.$, IFI $=0.903$, RMSEA $=0.067, \mathrm{LO}=0.061, \mathrm{HI}=0.074$ ). After these confirmatory analyses, we evaluated the discriminant validity of the scales through the Average Variance Extracted (AVE) and Composite Reliability (CR - Fornell \& Larker, 1981; Hair, Black, Babin, Anderson, 2010), which indicated that almost all scales presented an AVE higher or close to the 0.50 reference value and a CR above 0.70 (see Table 1).

After the definitions of the items in each scale assured a good reliability and acceptable discriminant validity, we conducted multiple linear regressions on the overall sample with the purpose of testing the main hypotheses. Furthermore, to avoid any possible problem of discriminant validity affecting the test of hypothesis, we conducted multicollinearity analyses and found that it did not influence the relationship between variables presented in our models (Shiu, Pervan, Bove and Beatty, 2011). Additionally, to avoid any risk of spurious relationships, we drew on the recommendation of Austin, Mamdani, Juurlink and Hux (2006) and Picard and Berk (1990). We randomly split the sample into two subsamples, and ran all the linear regressions on both. We repeated this procedure three times. Finally, we compared the resulting coefficients from the six subsamples with the coefficients of the original linear regressions based on the overall sample. In doing so, whenever coefficients in the overall sample presented statistical significance, if at least one of the coefficients was not significant in one subsample, we

Table 1

Construct reliability and convergent and discriminant validity.

\begin{tabular}{lllll}
\hline & CR & AVE & MSV & ASV \\
\hline Promotion values beliefs & 0.88 & 0.52 & 0.45 & 0.18 \\
Structural changes & 0.77 & 0.46 & 0.25 & 0.06 \\
Surveillance technologies & 0.84 & 0.73 & 0.38 & 0.09 \\
Manufacturing technologies & 0.69 & 0.43 & 0.38 & 0.15 \\
Positive emotions & 0.89 & 0.62 & 0.79 & 0.26 \\
Negative emotions & 0.79 & 0.48 & 0.79 & 0.24 \\
IRB & 0.87 & 0.63 & 0.11 & 0.08 \\
OCBI & 0.84 & 0.55 & 0.10 & 0.07 \\
OCBO & 0.77 & 0.45 & 0.11 & 0.07 \\
ORB & 0.91 & 0.51 & 0.04 & 0.03 \\
\hline
\end{tabular}

Note: $\mathrm{CR}=$ Construct reliability; $\mathrm{AVE}=$ average variance extracted; MSV = maximum shared variance; ASV = average shared variance. reported that finding in the respective table.

\subsection{Measures}

\subsubsection{Individual and contextual variables}

To control for individual factors we collected socio-demographic variables such as age, gender (dummy variable: $1=$ Male; $0=$ Female), and education level ( 1 = Primary; $2=$ Secondary; $3=$ Graduation; $4=$ Master $/ \mathrm{PhD}$ ). In addition, we measured contextual work-related variables such as professional experience $(1=\leq 1$ year; $2=$ between 2 and 3 years; $3=4-5$ years; $4=6-10$ years; $5=\geq 10$ years), type of contract ( $0=$ non-temporary contract; $1=$ temporary contract), team size (number of people composing their team: $1=\leq 3$ members; $2=$ between 4 and 9 members; $3=$ between 10 and 19 members; $4=>20$ members), and organization size (number of people in the organization: $1=\leq 10 ; 2$ = between $1150 ; 3=51100 ; 4$ = between 101250 ; $5=$ between $251500 ; 6=>500$ people).

\subsubsection{Socio-ideological organizational controls (SIOC)}

We used the Socio-Ideological Organizational Controls Scale (SIOCS), developed by Costa, Duarte, and Palermo (2014) to measure four control dimensions. This scale relies on the theoretical concepts suggested by Gabriel (1999), which highlight how an actor evaluates the dominant beliefs and procedures promoted by his/her organization. The SIOC consists of 18 items that measure the four socio-ideological dimensions of organisational controls, but to assure a good reliability we eliminated some items: i) promotion of new values and beliefs (7 items, e.g. "This organization values teamwork"; "this organization promotes individual initiative of employees";); ii) structural changes (4 items, e.g. "people change between professional roles with great frequency"; "This company is always creating new departments and extinguishing others"); iii) changes in manufacturing technologies (3 items, e.g. "there are regular changes in how work is done"; "I feel that more and more new technologies are introduced in order for me to perform my job"); iv) changes in surveillance technologies (2 items, e.g. "much of my work is now directly controlled by automatic systems"; "due to new technology, work is increasingly controlled"). We asked participants to express their views through a 5-point scale ranging from 1 (strongly disagree) to 5 (strongly agree), with higher scores indicating more perception of promotion of values and beliefs, and higher perception of structural changes, changes in manufacturing and surveillance technologies. The four subscales showed a good reliability: Cronbach $\alpha=0.88$ for promotion of values and beliefs; 0.76 for structural changes; 0.68 for changes in manufacturing technologies; and 0.84 for changes in surveillance technologies.

\subsubsection{Emotions}

We assessed employees' emotions by means of the abridged, internationally validated version of the Positive and Negative Affect Schedule (PANAS) (Thompson, 2007). This version of the scale is based on the original PANAS, developed by Watson, Clark, and Tellegen (1988), and measures two relatively independent dimensions of affect: 
positive ( 5 items: attentive, determined, alert, inspired, and active) and negative (4 items: being afraid, nervous, upset, and hostile, one item was excluded from the original scale). We asked participants to rate on 7 -point frequency scale $(1=$ never, $7=$ always $)$ how frequently they felt the above emotions in their workplace. We used the average value of the scores for both PA and NA. In each scale, higher scores correspond to high frequency of, respectively, positive and negative emotions in the workplace. These two subscales also showed good reliability, specifically Cronbach's $\alpha=0.89$ for PA and 0.79 for NA.

\subsubsection{Productive organizational behaviours}

We used the scale developed by Williams and Anderson (1991) to measure the productive organizational behaviours. However, we eliminated some items to assure a good reliability of the measurement. The following three types of organizational behaviours were assessed: employees' in-role behaviours (IRB), i.e., behaviours that are recognized by the formal reward policies and are part of the job requirements (4 items, e.g. "Performs the tasks that are expected"; "completes assigned duties on time"); organizational citizenship behaviours benefitting the individuals (OCBI), i.e., behaviours that benefit specific individuals, which indirectly can also contribute to the effectiveness of the organizational performance ( 5 items, e.g. "helps others who have been absent"; "share information with colleagues"); and organizational citizenship behaviours benefitting the organization (OCBO) (4 items, e.g. "gives advance notice when unable to come to work"; "adheres to informal rules devised to maintain order"). The scale was scored on a 5-point Likert type scale ranging from 1 (strongly disagree) to 5 (strongly agree). The three subscales showed good reliability: Cronbach $\alpha=0.87$ for IRB; 0.83 for OCBI; 0.77 for OCBO.

\subsubsection{Organizational resistant behaviours (ORB)}

We measured resistant behaviours using the organizational retaliatory behaviour scale (Skarlicki \& Folger, 1997), as suggested by Collinson (1994) and Lawrence and Robinson (2007). Such behaviours refer to actions that violate organizational norms in a way that is detrimental both to the organization per se, and to its members (e.g. "purposefully damaging equipment or sabotaging work processes"; "intentionally slowing one's work"). From the original 17 items of the scale we used 10, which assured a good reliability. These items were scored based on a Likert scale response format ranging from 1 (never in the last month) to 5 (six or more times in the past month). Higher scores reflect high frequency of resistant behaviours. The internal reliability of this scale produced a satisfactory result: Cronbach's $\alpha=0.90$.

\section{Results}

\subsection{Correlations amongst the main study variables}

Correlational analyses showed that some socio-demographic and contextual variables do present statistically significant correlations with SIOC, emotions, and organizational behaviours (Table 2). From these, the correlation between age and ORB $(r=-0.20)$ can be highlighted, suggesting that older employees tend to report less resistance toward perceived organizational controls. Correlational scores between the SIOC dimensions indicate that the four measures assess separate constructs. Promotion of values and beliefs and manufacturing technologies are not significantly associated $(r=-0.02)$, although the correlation between the other dimensions shows low to moderate positive correlations ( $r$ between 0.15 and $0.32, p<0.01$ ). A higher correlation emerges between the changes in surveillance technologies and in manufacturing technologies $(r=0.49)$, indicating that changes to the ways in which work is performed tend to be associated with changes in the ways work is controlled. Emotions seem to be clearly associated with perceived SIOC, mostly the promotion of values and positive emotions $(r=0.59)$ and inversely with negative emotions $(r=0.45)$.

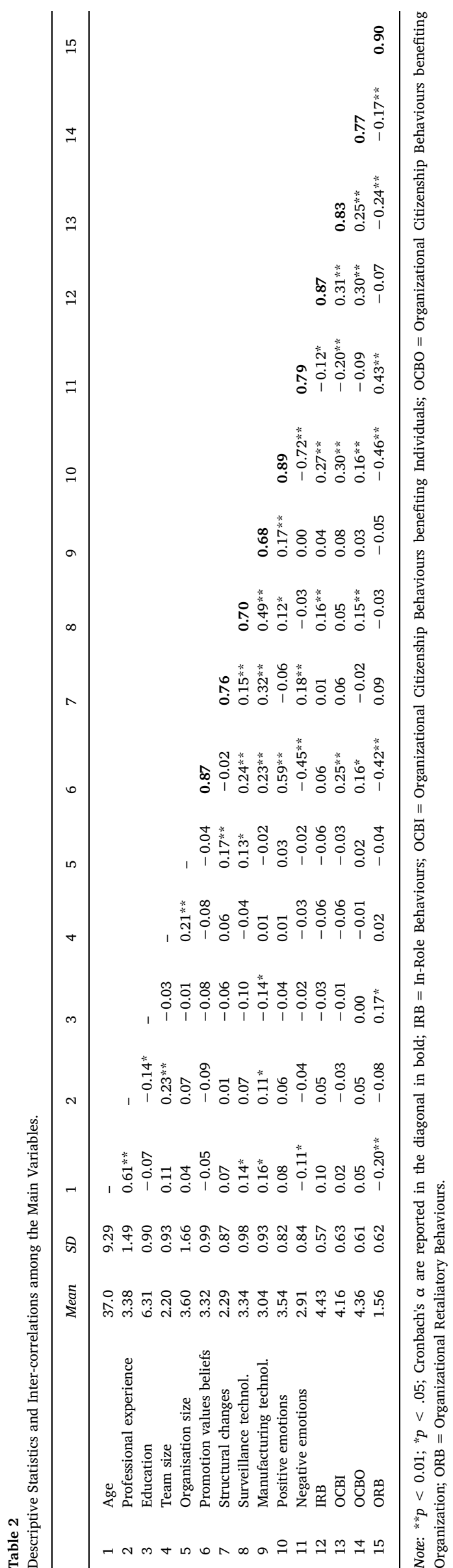


Table 3

Hierarchical Multiple Regression Analyses Using Positive and Negative Emotions as the Criterion Variables.

\begin{tabular}{|c|c|c|c|c|}
\hline \multirow[t]{2}{*}{ Predictor } & \multicolumn{2}{|c|}{ Positive Emotions } & \multicolumn{2}{|c|}{ Negative Emotions } \\
\hline & Step 1 & Step 2 & Step 1 & Step 2 \\
\hline (Intersection) & $3.44^{* *}$ & $1.42^{* *}$ & $3.52^{* *}$ & $4.68^{* *}$ \\
\hline Gender (male as dummy) & 0.01 & 0.02 & -0.06 & -0.08 \\
\hline Age & 0.08 & 0.07 & -0.12 & $-0.14 *$ \\
\hline Professional experience & -0.04 & 0.01 & 0.09 & 0.05 \\
\hline $\begin{array}{l}\text { Type of contract (temporary as } \\
\text { dummy) }\end{array}$ & 0.10 & $0.11 *$ & -0.10 & $-0.10 * i$ \\
\hline Education & -0.04 & 0.02 & -0.02 & -0.05 \\
\hline Team size & -0.01 & 0.02 & -0.02 & -0.04 \\
\hline Organisation size & 0.02 & 0.06 & -0.02 & -0.07 \\
\hline Promotion values & & $0.60^{* *}$ & & $-0.50 * *$ \\
\hline Structural changes & & -0.08 & & $0.17^{*}$ \\
\hline Surveillance technol. & & -0.09 & & 0.08 \\
\hline Manufacturing technol. & & 0.09 & & 0.02 \\
\hline$\Delta \mathrm{R}^{2}$ & & 0.35 & & 0.25 \\
\hline Adjusted $\mathrm{R}^{2}$ & 0.01 & 0.36 & 0.01 & 0.26 \\
\hline $\mathrm{F}$ value & $0.818 \mathrm{~ns}$ & 17.545 & $1.342 \mathrm{~ns}$ & 11.620 \\
\hline
\end{tabular}

Note: $\beta$ standardized coefficients presented a $t$ test with ${ }^{*} p<0.05,{ }^{* *} p<0.01$; † not significant in some subsamples.

\subsection{Predictors of emotions and of organizational behaviours}

We conducted Multiple Hierarchical Linear Regression (MHLR) analyses to assess the role of the four dimensions of perceived SIOC in predicting emotions, productive and resistance behaviours. In step 1 for each of the criterion variables, we always included individual (gender, age, and educational level) and contextual variables (professional experience, type of contract, team size, and organization size) to control their potential role in the main outcomes. In Step 2 we added the four dimensions characterizing the perceived SIOC (promotion of values, structural changes, surveillance technology changes, and manufacturing technology changes) to the models for understanding the unique contribution of SIOC dimensions over the baseline individual and work contextual variables.

Table 3 shows separate MHLR analyses for predicting positive and negative emotions. In step 1 we observed that no individual and contextual variables predict positive emotions. However, in step 2, two dimensions of SIOC explain it significantly, with $36 \%, F$ (11, $317)=17.54, p<.001$. More specifically, a greater perception of promotion of values and beliefs, $\beta=0.60, t(317)=12.75, p<.001$, retains a significant contribution to the explanation of variance of positive emotions in the workplace.

Similarly, in step 1, individual and contextual variables are not significant predictors of negative emotions. In step 2, adding SIOC dimensions as predictors also results in a substantially significant increase in the amount of variance in negative emotions, $R^{2}$ change $=0.25, F$ $(11,317)=11.62, p<.001$. Lower perception of promotion of values and beliefs, $\beta=-0.50, t(317)=-9.88, p<.001$, predict greater negative emotions in the workplace. As a whole, the final model accounts for $26 \%$ of the total variance in negative emotions.

These first regressions suggest that the perception of discourses promoting organizational values in the workplace are likely to predict high positive emotions and low negative ones.

Regarding the role of perceived SIOC on employees' organizational behaviours, we found that only some dimensions of SIOC are relevant predictors of Organizational Citizenship Behaviours benefitting Individuals (OCBI) and of Resistance Behaviours (ORB) (See Table 4). The proportion of additional variance contributed by SIOC dimensions accounted for by individual and contextual variables ranges from $4 \%$ (OCBI) to $10 \%$ (ORB). However, for IRB and for organizational citizenship behaviours benefitting the organization (OCBO), demographics, contextual work variables, and SIOC scores do not predict significant variance.

A closer look at our findings shows that individual and contextual variables do not explain a significant amount of variance in OCBI. However, when adding perceived SIOC dimensions in Step 2, we found a significant change in predicting OCBI, adjusted $R^{2}$ change $=0.04, F$ $(11,317)=3.23, p<.001$. In particular, employees' higher perception of the promotion of values is a significant contributor to higher OCBI, $\beta=0.24, t(317)=4.18, p<.001$. These results highlight that SIOC predict OCBI, but not IRB behaviours and OCBO. Such outcomes lead to a partial acceptance of Hypothesis 1 .

As shown in Table 4, in step 1 age is negatively associated with ORB in the workplace, $F(7,321)=3.44, \beta=-0.23, p=.002$, adjusted $R^{2}=0.05$, indicating that older employees tend to retaliate less against their organizations. In step 2, adding SIOC dimensions explains additional variance of ORB, which is significantly higher (adjusted $R^{2}$ change $=0.11, p<.001)$ than in step $1, F(11,317)=6.78$, $p<.001$. In particular, employees' low perception of the promotion of values, $\beta=-0.34, t(312)=-6.38, p<.001$, is a significant predictor of lesser ORB, and $16 \%$ of the variance is accounted for by this model. These results highlight that resistance significantly decreases when employees perceive certain values that are promoted by their companies. Although these results do not allow us to accept Hypothesis 2 in full, they provide interesting insights to the debate on SIOC, especially tied to the belief that SIOC can reduce employees' resistance potential.

\subsection{Mediation analyses}

The results we illustrated in the previous section allow us to partially accept Hypotheses 1 and 2. They highlight that SIOC are associated not only with emotions - as we observed in the previous models but also with the way individuals interact with one another. This interaction can be tied particularly to possible cooperation and mutual support (as measured by OCBI) or to resistance reduction (ORB). Our results place greater attention to the extent of mutual association between the different dimensions of perceived SIOC as well as to the possible mediation exerted by emotions. For a clearer perspective, we tested the mediation hypotheses. Given that the promotion of values is related only to OCBI and ORB, we computed only two parallel multiple mediator models: one model for OCBI (Hypothesis 3) and another one for ORB (Hypothesis 4). We tested the mediational hypotheses following Preacher and Hayes, (2008), and Hayes, (2013) suggestions on parallel multiple mediator models. We entered both positive and negative affect as mediators in the relationship between the predictor (promotion of values) and the criterion variables (OCBI and ORB). This enabled us to test simultaneously each affective state while accounting for the shared association between them.

We used the PROCESS macro for SPSS, provided by Hayes (available at http://www.processmacro.org), to produce the estimates. This macro estimates the regression outputs following the stepwise procedure suggested by Baron and Kenny (1986). It also generates statistics for the inferential testing of indirect effects. By showing the effects of the Sobel test, it follows a normal theory approach (Sobel, 1982) based on the assumption that the indirect effect is normally distributed. It also provides a non-parametric approach by estimating bootstrap confidence intervals (CIs) that do not require the sampling distribution of the indirect effect to be normal, as is often the case in many mediational analyses. This occurs even when each of the variables that are used to calculate the indirect effect are normally distributed (Edwards \& Lambert, 2007). The results of the unstandardized and standardized regression coefficients, as well as the t-test, the Sobel test, and the $95 \%$ bias-corrected bootstrap confidence intervals (using 1000 bootstrap samples) are summarized in Table 5.

As Table 5 shows, employees who acknowledged a greater perception of the promotion of values also expressed greater frequency of positive emotions $(B=0.48, \beta=0.59, p<.001)$. Those with greater 
Table 4

Hierarchical Multiple Regression Analyses using Organizational Behaviours as the Criterion Variables.

\begin{tabular}{|c|c|c|c|c|c|c|c|c|c|c|}
\hline \multirow[t]{2}{*}{ Predictor } & \multicolumn{2}{|l|}{ IRB } & \multicolumn{3}{|l|}{ OCBI } & \multicolumn{2}{|l|}{ Осво } & \multicolumn{3}{|l|}{ ORB } \\
\hline & Step 1 & Step 2 & Step 1 & Step 2 & Step 3 & Step 1 & Step 2 & Step 1 & Step 2 & Step 3 \\
\hline (Intersection) & $4.23^{* *}$ & $3.92^{* *}$ & $4.23^{* *}$ & $3.45^{* *}$ & $3.20 * *$ & $4.22^{* *}$ & $3.71^{* *}$ & 1.37 & 2.14 & 1.186 \\
\hline Gender (male as dummy) & -0.10 & -0.12 & -0.06 & -0.07 & -0.07 & -0.05 & -0.07 & 0.00 & -0.01 & 0.00 \\
\hline Age & 0.12 & 0.10 & 0.09 & 0.08 & 0.06 & 0.04 & 0.03 & $-0.24^{* *}$ & $-0.26^{* *}$ & $-0.23^{* *}$ \\
\hline Professional experience & -0.03 & -0.02 & -0.05 & -0.02 & -0.03 & 0.05 & 0.07 & 0.09 & 0.06 & 0.05 \\
\hline Type of contract (temporary as dummy) & 0.05 & 0.05 & -0.07 & -0.06 & -0.09 & -0.05 & -0.06 & -0.03 & -0.03 & 0.00 \\
\hline Education & -0.01 & -0.01 & -0.02 & 0.02 & 0.01 & 0.01 & 0.03 & $0.16 * \dagger$ & $0.14 * \dagger$ & $0.15^{*} \dagger$ \\
\hline Team size & -0.06 & -0.04 & -0.03 & -0.02 & -0.02 & -0.02 & 0.00 & 0.04 & 0.03 & 0.04 \\
\hline Organisation size & 0.08 & 0.06 & -0.02 & -0.02 & -0.04 & 0.04 & 0.02 & -0.05 & -0.10 & -0.07 \\
\hline Promotion values & & 0.04 & & $0.24 * *$ & 0.08 & & $0.14 * \dagger$ & & $-0.45^{* *}$ & $-0.26^{* *}$ \\
\hline Structural changes & & -0.01 & & 0.06 & 0.08 & & -0.02 & & 0.10 & 0.06 \\
\hline Surveillance technol. & & $0.17^{* *}$ & & -0.01 & 0.01 & & $0.17^{*}$ & & 0.13 & 0.10 \\
\hline Manufacturing technol. & & -0.05 & & 0.01 & 0.02 & & -0.08 & & 0.00 & 0.02 \\
\hline Positive Emotions & & & & & $0.26^{* *}$ & & & & & $-0.18^{* *}$ \\
\hline Negative Emotions & & & & & 0.00 & & & & & $0.14 * \dagger$ \\
\hline$\Delta R^{2}$ & & 0.01 & & 0.04 & 0.04 & & 0.02 & & 0.19 & 0.06 \\
\hline Adjusted $R^{2}$ & 0.01 & 0.01 & 0.00 & 0.04 & 0.08 & 0.00 & 0.02 & 0.06 & 0.25 & 0.31 \\
\hline$F$ value & $1.536 \mathrm{~ns}$ & $1.705 \mathrm{~ns}$ & $.747 \mathrm{~ns}$ & 2.320 & 3.230 & $0.435 \mathrm{~ns}$ & $1.659 \mathrm{~ns}$ & 3.444 & 6.776 & 9.705 \\
\hline
\end{tabular}

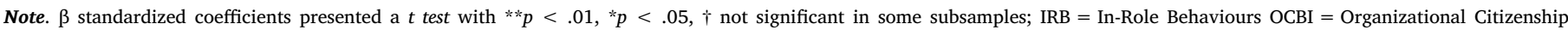
Behaviours benefiting Individuals; OCBO = Organizational Citizenship Behaviours benefiting Organization; ORB = Organizational Retaliatory Behaviours.

positive emotions reported greater OCBI after controlling for the promotion of values $(B=0.21, \beta=0.27, p<.001)$. The total effect of the promotion of values on OCBI is significant $(B=0.16, \beta=0.25$, $p<.001$ ), but the direct effect of the promotion of values on OCBI is non-significant after controlling for emotions $(B=0.07, \beta=0.11$, $p<$.0797). More importantly, the perception that the work

Table 5

Regression Results for Parallel Multiple Mediations on the Relationship between Promotion of Values and Organizational Behaviours through Affective States.

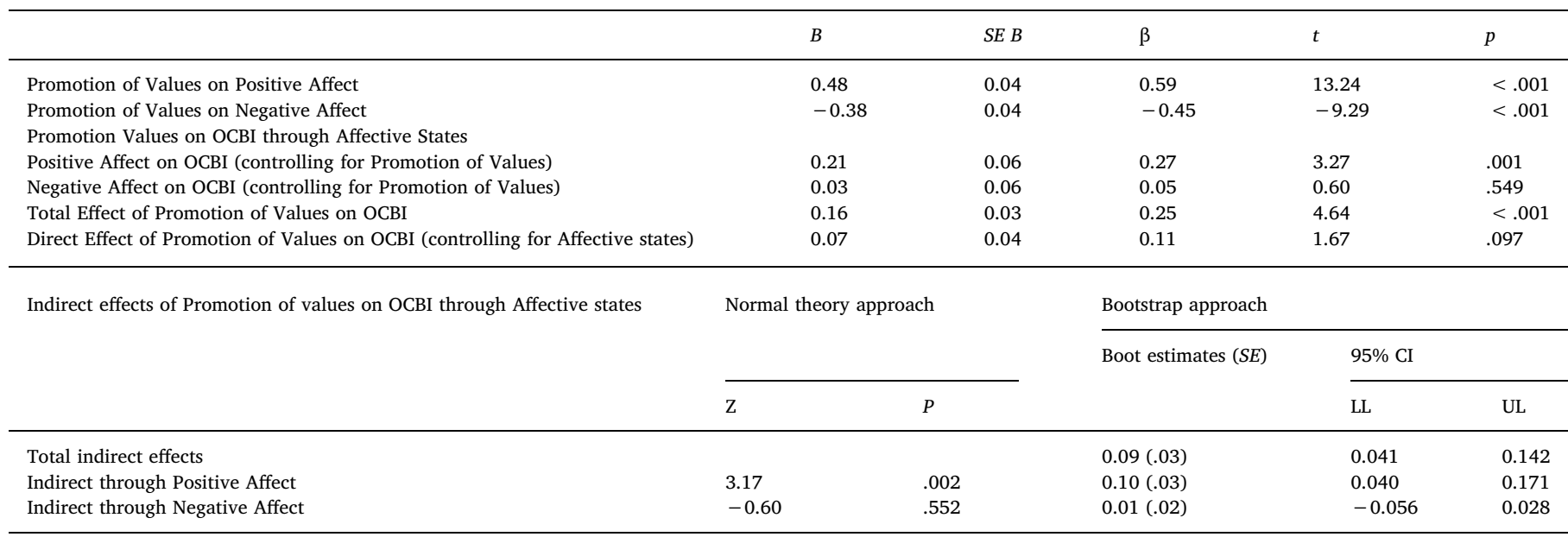

Promotion Values on ORB through Affective States

\begin{tabular}{|c|c|c|c|c|c|}
\hline & $B$ & $S E B$ & $\beta$ & $t$ & $p$ \\
\hline Positive Affect on ORB (controlling for Promotion of Values) & -0.15 & 0.06 & -0.20 & -2.66 & .008 \\
\hline Negative Affect on ORB (controlling for Promotion of Values) & 0.14 & 0.05 & 0.19 & 2.75 & .006 \\
\hline Total Effect of Promotion of Values on ORB & -0.26 & 0.03 & -0.42 & -8.42 & $<.001$ \\
\hline Direct Effect of Promotion of Values on ORB (controlling for Affective States) & -0.13 & 0.04 & -0.22 & -3.70 & $<.001$ \\
\hline
\end{tabular}

Indirect effects of Promotion of values on ORB through Affective states
Normal theory approach

$$
\text { Z }
$$

Total indirect effects

Indirect through Positive Affect

Indirect through Negative Affect

$-2.60$

-2.60
-2.63

$\mathrm{Z} \quad P$

Bootstrap approach

Bootstrap estimates (SE)

.009

.009

$-0.13(0.02)$

$-0.07(0.03)$

$-0.05(0.02)$

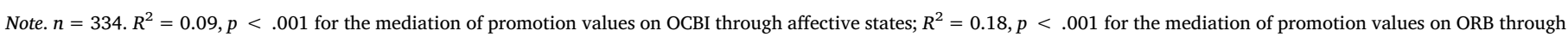

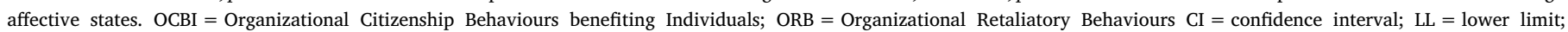
$\mathrm{UL}=$ upper limit. Bootstrap sample size $=1000$. 
environment promotes values relates to higher positive emotions frequency, which in turn is positively related to high OCBI. This indirect effect is positive, indicating that the greater the level of perception of values, the greater the frequency of positive emotions, and in turn, the greater the OCBI. Regardless of which approach we used to test for the indirect effects, the results were similar (normal theory approach: $\mathrm{Z}=3.17, p=.002 ; 95 \%$ bootstrap $\mathrm{CI}=0.04$ to 0.17 , excluding zero), partially supporting Hypothesis 3. However, the indirect effect of the negative affect was not significant $(\mathrm{Z}=-0.06, p=.55)$, indicating that the negative affect does not help to explain the relationship between the perception of the promotion of values and OCBI. Overall, the multiple mediator model for OCBI was significant, $F(3,330)=12.22$, $p<.001, R^{2}=0.09$.

Regarding the affective states mediation on the relationship between the promotion of values and the ORB, after checking for the promotion of values $(B=-0.26, \beta=-.42, p<.001)$, we found a reverse relationship between positive emotions and ORB $(B=-.15$, $\beta=-.20, p<.001)$. This indicates that participants who acknowledge a high occurrence of positive emotions at work, report lower ORB. The total effect of the promotion of values on ORB is significant. However, after checking the affective states, the direct relationship between these two variables was reduced $(B=-0.13, \beta=-0.22, p<.001)$. With regard to the two indirect effects, the negative relationship between the promotion of values and ORB through positive emotion was significant normal theory approach: $\mathrm{Z}=-2.60, p=0.009$; $95 \%$ CI bootstrap $=-0.126$ to -0.025 , not containing zero. The negative relationship between the promotion of values and ORB through negative emotion was also significant (normal theory approach: $\mathrm{Z}=-2.63$, $p=.009 ; 95 \%$ CI bootstrap $=-0.094$ to -0.019 , not containing zero). Such outcomes allow us to argue that positive emotions emerge in environments where employees perceive the values promoted by their organizations, and simultaneously prevent the occurrence of negative emotions.

Overall, the mediator model for ORB is significant, $F$ (3, $330)=30.57, p<.001, R^{2}=0.26$, which supports Hypothesis 4 . This hypothesis predicted the mediating role of both positive and negative affect on the relationship between high perception of values' promotion and low ORB.

Our results enable us to argue that perceived SIOC, specifically related to the promotion of values, are an important predictor for the experience of positive emotions and reduction of negative emotions at work. In turn, higher positive emotions at work predict high OCBI and low ORB. In organizations that promote shared beliefs for the successful pursuit of organizational objectives, individuals report higher positive emotions and lower negative ones. This dynamic can be associated with fewer resistance behaviours.

\section{Discussion}

The literature on Socio-Ideological Controls (SIOC) stresses the debate on whether organizations' use of controls that "rely on enculturation, identification with company objectives, and forms of processes of subjectification" (Styhre, 2008, p. 640; El-Sawad \& Korczynski, 2007) can give rise to workplace resistance (Casey, 1996, 1999; Gabriel, 1999; Sewell \& Wilkinson, 1992;). In reflecting on this debate we drew on Fineman's (Fineman \& Sturdy, 1999; Fineman, 2001) and Ashforth and Humphrey's (1995) contributions, which highlight the central role of emotions for understanding organisational life and control dynamics.

We started by singling out each of the dimensions constituting SIOC (Gabriel, 1999). We did so for better understanding the impact that each one of them had on productive behaviours, our first research goal. We then looked at how those dimensions were associated with possible resistance, our second goal. We observed that role expected behaviours (IRB) and cooperation with the organisation (OCBO) are associated with perception of changes in surveillance technologies. Instead, the perception of the promotion of values is consistently associated with higher cooperation with other individuals and the organisation (OCBI, OCBO), and with less resistance (ORB). However, those aspects were not linked to structural changes and to changes in manufacturing technologies/work processes (which also constituted dimensions of SIOC (Gabriel, 1999)).

Finally, for evaluating the role of emotions, we started from the argument about emotions standing at the very core of organizational control (Fineman, 2001), and focused on this intermediate level for better understanding the control-resistance dyad. We can argue that actors' high experience of positive emotions and low experience of negative ones are linked with the perception of organization's socioideological controls in the workplace. From our findings, we observed that the dimension that deserves more attention is the perception of promotion of values. It is strongly associated with behaviours that are desirable to companies, such as the presence of cooperative behaviours and the reduction of resistance behaviours. It is also linked to a stronger experience of positive emotions and weaker experience of negative emotions.

Our findings are in line with the theory explaining the emergence of resistance as a response to the presence of negative emotions. However, they also suggest that the presence of positive emotions has a greater role in reducing resistance behaviours. Research aligned with such views suggests that resistance to control and display of misbehaviour occur because employees feel frustrated by controls that reduce their autonomy and their sense of identity, and that generate injustice (Lawrence \& Robinson, 2007). However, our study shows that positive emotions are a more significant predictor of the process of individuals' subjectification. Colonizing individuals from the inside is connected to the promotion of discourses that create an overlap between the meaning that individuals attribute to their workplace, and the instrumental values advertised by the organization through those same discourses. To some extent we can argue that individuals' subjectification is related not only to the identification with the organizational objectives (El-Sawad \& Korczynski, 2007; Styhre, 2008), but also to the ways used by the organization to achieve those objectives. The harmonization of meanings that occurs in the subjectification process can promote a positive emotional setting that, in turn, can explain high cooperative behaviours amongst individuals (as our data show). On the contrary, lower feelings of positive affect in the workplace are related to employees' care for the organization and for their colleagues. This can generate resistance in the form of both withdrawal and retaliatory behaviours. We can speculate that a lack of positive emotions generates a decrease in the sense of belongingness (or membership) which then pushes employees not to adhere to the norms of the organization.

In terms of research challenges, we acknowledge the difficulty of portraying the depth of the phenomenon we analysed mainly due to the methodological tools we adopted. A first limitation is linked to our cross-sectional design, which reduces the possibility of inferring causal relations between the implementation of SIOC, the emergence of emotions, and the outcome behaviours. In spite of using self-reported measures, the existing experimental evidence allows us to be confident about the relationships between emotions and performance measures (Gillet et al., 2013; Ilies et al., 2006;). There is not enough research exploring the relationships between organizational controls and their direct effects over emotions and behaviours. In fact, one could argue that certain emotional states can enable people to perceive some types of discourses easily, or pay more attention to on-going changes within their organizations, or even lead to report certain kinds of behaviours more than others. Some experimental studies (e.g. Jensen \& Raver, 2012), as well as studies on discursive analysis (e.g. Erkama, 2010), suggest: (1) a causal relationship between new controls and the emotions and behaviours they might give rise to; and that (2) those controls influence the construction of individuals' self-identities and emancipation strategies. Experimental studies and comparative case studies, for example, could help overcome those issues in the future. Some 
variables might give rise to measurement issues in terms of acceptable values of AVE (Table 1); however, none of those variables is related to any of the major findings of the study. We appreciate ethnographic or narrative research could reveal more in terms of how actors relate to organizational discourses, how they construct their identities, share meanings with others, and feel about working in their specific setting. Nevertheless, the aim of our study was not an in-depth exploration of how actors constructed and shared the meaning of organizational control and resistance.

With regard to the single variance bias, we could have possibly reduced it if participants from the same company would have assessed the measures concerning the controls, the emotional and behavioural outcomes. Furthermore, since we have not collected the information about the company, it was not possible to aggregate individual answers by companies, restricting this way our findings to individual perspective. This restriction in the sampling procedure implies a limitation relatively to the interpretation of estimates in the regression models because is not possible to control for company specific effects (constraints on variance and/or omitted variables connected to the different companies). A more systematic sampling method with companies' information allowing a multi-level study would also enabled to compare the effects of perceived SIOC aggregated by companies, against other organizational measures that usually influence productive and resistant behaviours. Although we adopted the individual level of analysis, we acknowledge that it might be worth for future research to adopt a macro level, instead. The latter would allow exploring the SIOC effects from a different angle. It would allow researchers to consider the cross level effects between SIOC and behaviours, and clarify if the SIOC taken at an organizational level are more or less explanative than their perceptions at an individual level. Ultimately, comparing the outcomes that emerge from the two different levels of analysis could provide clearer understanding of the dynamics characterising control, emotions and resistance. In our case, the macro level would have produced aggregated values emphasizing intra and inter-firms variance - an interesting aspect, but not one we had set out to explore. Furthermore, the inclusion of variables related with bureaucratic controls would have allowed us to illustrate the interplay between the traditional controls and SIOC and the extent of the differences and similarities between the outcomes they generate.

The inclusion of variables related to the possible disengagement and to employees' organizational identity might contribute to an understanding of the effects that perceived discourses produce in individuals. In terms of resistance, the development of new scales capturing other discursive aspects could enable the evaluation of whether those discourses constitute a separate dimension of resistance behaviours, or if they overlap with them. It could be interesting to understand the extent to which the discursive aspects of resistance may be a mediator between controls and behaviours, or if they would only represent a way for voicing employees' concerns with less impact over their performance. Future research could explore more specifically the link between SIOC and discursive resistance.

\section{Conclusion}

In summary, we can argue that employees' perceptions of the promotion of organizational beliefs is the socio-ideological control dimension that, more than any of the others, has the strongest relationship with productive behaviours and the weakest one to resistance. This dimension is also the one that induces emotional processes. It generates positive emotions, and reduces the emergence of negative ones. Both mediate the relationships with behaviours. The weak relationships between the different dimensions of SIOC and the identification of IRB behaviours and ОСBO lead us to argue that such types of control are less effective for increasing productivity compared to technocratic ones. Additionally they do not seem to enact the emotional processes we focused on, in this paper. Positive emotional states can contribute to employees' greater sense of wellbeing, to their closer relations with the organization (springing from the higher OCBI) and to a reduction of their dissent. Such conditions facilitate the implementation of changes. What at a first glance might seem like a "paradise" scenario in organizations' attempts to control individuals, can actually present some issues. In fact, organizations that heavily promote values, and seek to culturally dominate individuals by shaping their identities may end up generating higher levels of emotional stress (Chiu \& Tsai, 2006) in their employees. Creating an acritical environment for reducing dissent also reduces the innovation potential for the organization (DeDreu, 2010; Vigoda-Gadot, 2007), and ineffective dynamics based on voluntarist behaviours (Reynolds, Shoss \& Jundt, 2015).

Our findings invite us to interpret (and to deal with) the dimensions associated with SIOC in a new way: by separating the discursive dimension from the ones linked to organizational practices (e.g. surveillance technology, structure) because of the different emotional outcomes they can generate.

With this deeper look into the control-resistance dyad, we can conclude that the discursive promotion of values and beliefs aimed at aligning employees' perspectives with organizational success reduces resistance behaviours. This claim is in line with scholars arguing that subtle and deep ways of controlling individuals eliminate psychological and emotional barriers to organizational controls (Casey 1996, 1999; Sewell \& Wilkinson, 1992). Our study suggests that in companies that do not promote values and beliefs through discursive practices, retaliatory behaviours are more likely to occur. This is entirely explained by the findings showing the reduction of employees' positive emotions. We can also argue that other types of discourses could be explored, for example those constructed on fear messages, threat (Tannenbaum et al., 2015), and punishment against transgressors (Simon, 2007). Such discourses would offer the opportunity to understand aspects of organizational life that, at a first glance, appear blurry (Fleming, 2013; Gabriel, 1999). It is our belief that deeper research on those topics can shed light on the extent to which discursive practices can legitimize authority, implement coercive control systems, and trigger negative emotions and resistance behaviours.

Our study emphasizes the instrumentality that the promotion of values and beliefs can have on organizations. Aligning individuals' perspectives to organizational ones through discourses aimed at promoting values, attitudes and beliefs is relevant to companies because it can reduce recalcitrance (ORB), and it can foster cooperation between individuals (OCBI). Our study also shows the perils of homogenizing organizational culture by producing dominant discourses. The lack of resistance or the reliance on the extra-role behaviours can make organisation conformism-reliant, and lazy in promoting bottom-up change and innovation.

\section{Conflict of interest}

There are no conflicts of interests.

\section{Funding}

This research did not receive any specific grant from funding agencies in the public, commercial, or non-for-profit sectors.

\section{Acknowledgments}

We would like to thank Dr. Tiago Costa for his contribution to the initial phase of this research. We gained a lot from his comments and participation.

\section{References}

Alfes, K., Truss, C., Soane, E. C., Rees, C., \& Gatenby, M. (2013). The relationship between line manager behaviour, perceived HRM practices, and individual performance: 
Examining the mediating role of engagement. Human Resource Management, 52(6), 839-859.

Alvesson, M., \& Karreman, D. (2004). Interfaces of control. Technocratic and socioideological control in a global management consultancy firm Accounting. Organization and Society, 29(3-4), 423-444.

Ashforth, B. E., \& Humphrey, R. H. (1995). Emotion in the workplace: A reappraisal. Human Relations, 48(2), 97-125.

Austin, P. C., Mamdani, M. M., Juurlink, D. N., \& Hux, J. E. (2006). Testing multiple statistical hypotheses resulted in spurious associations: A study of astrological signs and health. Journal of Clinical Epidemiology, 59(9), 964-969.

Barley, S. R., \& Kunda, G. (1992). Design and devotion: Surges of rational and normative ideologies of control in managerial discourse. Administrative Science Quarterly, 39, 363-399.

Baron, R. M., \& Kenny, D. A. (1986). The moderator-mediator variable distinction in social psychological research: Conceptual, strategic and statistical considerations. Journal of Personality and Social Psychology, 51, 1173-1182.

Berry, C., Ones, D., \& Sackett, P. (2007). Interpersonal deviance, organizational deviance, and their common correlates: A review and a meta-analysis. Journal of Applied Psychology, 92(2), 410-424.

Beynon, H. (1975). Working for ford. Wakefiled: E.P. Publishing.

Casey, C. (1996). Corporate transformations: Designer culture, designer employees and 'post-occupational' solidarity. Organization, 3, 317-339.

Casey, C. (1999). Come, join our family: Discipline and integration in corporate organizational culture. Human Relations, 52(2), 155-178.

Chang, C.-H., Johnson, R. E., \& Yang, L.-Q. (2007). Emotional strain and organizational citizenship behaviours: A meta-analysis and review. Work and Stress, 21(4), 312-332.

Chiu, S. F., \& Tsai, M. C. (2006). Relationships among burnout, job involvement, andorganizational citizenship behavior. The Journal of Psychology, 140(6), 517-530.

Collinson, D. (1994). Strategies of resistance: Power, knowledge and subjectivity in the workplace. In J. Jermier, W. Nord, \& D. Knights (Eds.). Resistance in organizations (pp. 25-68). London: Routledge.

Combs, J., Liu, Y., Hall, A., \& Ketchen, D. (2006). How much do high-performance work practices matter? A meta-analysis of their effects on organizational performance. Personnel Psychology, 59, 501-528.

Costa, T., Duarte, H., \& Palermo, O. A. (2014). Control mechanisms and perceived organizational support: Exploring the relationship between new and traditional forms of control. Journal of Organizational Change Management, 27(3), 407-429.

Dalal (2005). A meta-analysis of the relationship between organizational citizenship behaviour and counterproductive work behaviour. Journal of Applied Psychology, 90(6), 1241-1255.

DeDreu, C. (2010). Team innovation and team effectiveness: The importance of minority dissent and reflexivity. European Journal of Work and Organizational Psychology, 11(3), 285-298.

Dischner, S. (2015). Organizational structure, organizational form, and counterproductive work behavior: A competitive test of the bureaucratic and post-bureaucratic views. Scandinavian Journal of Management, 31(4), 501-514.

Edwards, J. R., \& Lambert, L. S. (2007). Methods for integrating moderation and mediation: A general analytical framework using moderated path analysis. Psychological Methods, 12(1), 1-22.

El-Sawad, A., \& Korczynski, M. (2007). Management and music - The exceptional case of the IBM songbook. Group \& Organization Management, 32(1), 79-108.

Elfenbein, H. A. (2007). Emotion in organizations a review and theoretical integration. Academy of Management Annals, 1, 315-386.

Erkama, N. (2010). Power and resistance in a multinational organization: Discursive struggles over organizational restructuring. Scandinavian Journal of Management, 26(2), 151-165.

Etzioni, A. (1965). Organizations, control and structure. In J. March (Ed.). Handbook of organizations (pp. 650-677). Chicago: Rand McNally.

Fineman, S., \& Sturdy, A. (1999). The emotions of control: A qualitative exploration of environmental regulation. Human Relations, 52(5), 631-663.

Fineman, S. (1993). Emotions in organizations. London: Sage.

Fineman, S. (2001). Emotions and organizational control. In R. Payne, \& C. Cooper (Eds.). Emotions at work: Theory, research, and applications for management (pp. 219-240). London, UK: John Wiley and Sons Chichester.

Fleming, P., \& Sewell, G. (2002). Looking for the good soldier, Svejk: Alternative modalities of resistance in the contemporary workplace. Sociology, 36(4), 857-873.

Fleming, P. (2013). Down with big brother!' the end of 'corporate culturalism. Journal of Management Studies, 50(3), 474-495.

Fornell, C., \& Larker, D. (1981). Evaluating structural equation models with unobservable variables and measurement error. Journal of Marketing Research, 18, 39-50.

Frederickson, B. I. (1998). What good are positive emotions? Review of General Psychology, $2,300-319$.

Fredrickson, B. L. (2001). The role of positive emotions in positive psychology - The broaden-and-build theory of positive emotions. American Psychologist, 56(3), 218-226.

Frijda, N. H., \& Scherer, K. R. (2009). Emotion definitions (psychological perspectives). In K. R. Sander, \& K. R. Scherer (Eds.). Oxford companion to emotion and the affective sciences. New York: Oxford University Press.

Gabriel, Y., Geiger, D., \& Letiche, H. (2011). The marriage of story and metaphor. Culture and Organization, 17(5), 367-371.

Gabriel, Y. (1999). Beyond happy families: A critical reevaluation of the control-resistance-identity triangle. Human Relations, 52(2), 179-203.

Gillet, N., Vallerand, R. J., Lafreniere, M.-A. K., \& Bureau, J. S. (2013). The mediating role of positive and negative affect in the situational motivation-performance relationship. Motivation and Emotion, 37(3), 465-479.

Giorgi, S., Lockwood, C., \& Glynn, M. (2015). The many faces of culture: Making sense of
30 years of research on culture in organization studies. The Academy of Management Annals, 9(1), 1-54.

Hair, J., Black, W., Babin, B., \& Anderson, R. (2010). Multivariate data analysis. New Jersey: Pearson Prentice Hall.

Harris, L., \& Ogbonna, E. (2011). Antecedents and consequences of management - espoused organizational cultural control. Journal of Business Research, 64, 437-445.

Hayes, A. F. (2013). Introduction to mediation, moderation, and conditional process analysis: A regression-based approach. New York: Guilford Press.

Ilies, R., Scott, B. A., \& Judge, T. A. (2006). The interactive effects of personal traits and experienced states on intraindividual patterns of citizenship behavior. Academy of Management Journal, 49(3), 561-575.

Jensen, J. M., \& Raver, J. L. (2012). When self-management and surveillance collide: Consequences for employees' organizational citizenship and counterproductive work behaviors. Group \& Organization Management, 37(3), 308-346.

Jermier, J. M., Knights, D. E., \& Nord, W. R. (1994). Resistance and power in organizations. London: Routledge.

Jiang, K., Lepak, D., Hu, J., \& Baer, J. (2012). How does human resource management influence organizational outcomes? A meta-analytic investigation of mediating mechanisms. Academy of Management Journal, 55(6), 1264-1294.

Kanfer, R., \& Ackerman, P. L. (1989). Motivation and cognitive abilities: An integrative/ aptitude-treatment interaction approach to skill acquisition. Journal of Applied Psychology, 74(4), 657.

Kaplan, S., Bradley, J. C., Luchman, J. N., \& Haynes, D. (2009). On the role of positive and negative affectivity in job performance: A meta-Analytic investigation. Journal of Applied Psychology, 94(1), 162-176.

Kehoe, R. R., \& Wright, P. M. (2013). The impact of high-performance human resource practices on employees' attitudes and behaviors. Journal of Management, 39(2), 366-391.

Koy, A., \& Yeo, G. (2008). BIS sensitivity, negative affect and performance: Dynamic and multilevel relationships. Human Performance, 21(2), 198-225.

Krausert, A. (2017). The differentiation between professional and managerial employees: Broadening and integrating theoretical perspectives. Human Resource Management Review, 442-457.

Kunda, G. (2006). Engineering Culture: Control and commitment in a high-tech corporation. Philadelphia: Temple University Press.

Lawrence, T. B., \& Robinson, S. L. (2007). Ain't misbehavin: Workplace deviance as organizational resistance. Journal of Management, 33(3), 378-394.

Lazarus, R. S. (1982). Thoughts on the relations between emotion and cognition. American Psychologist, 37(9), 1019-1024.

Liao, H., Toya, K., Lepak, D., \& Hong, Y. (2009). Do they see eye to eye? Management perspectives of high-performance work systems and influence processes on service quality. Journal of Applied Psychology, 94(2), 371-391.

Lindebaum, D. (2012). I rebel-therefore we exist: Emotional standardization in organizations and the emotionally intelligent individual. Journal of Management Inquiry, 21(3), 262-277.

Lyubomirsky, S., King, L., \& Diener, E. (2005). The benefits of frequent positive affect: Does happiness lead to success. Psychological Bulletin, 131(6), 803-855.

Malmi, T., \& Brown, D. (2008). Management control systems as a package - opportunities: Challenges and research directions. Management Accounting Research, 19, 287-300.

McKenna, S., Garcia-Lorenzo, L., \& Bridgman, T. (2010). Managing, managerial control and managerial identity in the post-bureaucratic world. Journal of Management Development, 29(2), 128-136.

Ouchi, W. G., \& Maguire, M. A. (1975). Organizational control: Two functions. Administrative Science Quarterly, 20, 559-569.

Peters, T., \& Waterman, R. (1982). In search of excellence: Lessons from America's best-run companies. New York: Harper \& Row, Publishers.

Picard, R. R., \& Berk, K. N. (1990). Data splitting. The American Statistician, 44(2), $140-147$.

Podsakoff, P. M., MacKenzie, S. B., Lee, J.-Y., \& Podsakoff, N. P. (2003). Common method biases in behavioral research: A critical review of the literature and recommended remedies. Journal of Applied Psychology, 88(5), 879.

Podsakoff, P. M., MacKenzie, S. B., Podsakoff, N. P., Fiske, S. T., Schacter, D. L., \& Taylor, S. E. (2012). Sources of method bias in social science research and recommendations on how to control it. Annual Review of Psychology, 63, 539-569.

Preacher, K. J., \& Hayes, A. F. (2008). Asymptotic and resampling strategies for assessing and comparing indirect effects in multiple mediator models. Behavior Research Methods, 40(3), 879-891.

Raelin, J. A. (2011). The end of managerial control. Group \& Organization Management, 36(2), 135-160.

Reynolds, C., Shoss, \& Jundt, D. (2015). In the eye of the beholder: A multi-stakeholder perspective of organizational citizenship and counterproductive work behaviors. Human Resource Management Review, 25, 80-93.

Schoefer, K., \& Diamantopoulos, A. (2008). The role of emotions in translating perceptions of (in)justice into postcomplaint behavioral responses. Journal of Service Research, 11(1), 91-103.

Sewell, G., \& Wilkinson, B. (1992). Someone to watch over me': surveillance, discipline and the just-in-time labour process. Sociology, 26(2), 271-289.

Shiu, E., Pervan, S., Bove, L., \& Beatty, S. (2011). Reflections on discriminant validity: Reexamining the Bove et al: (2009) findings. Journal of Business Research, 64 497-500.

Simon, J. (2007). Governing through crime: How the war on crime transformed American democracy and created a culture of fear. New York: Oxford University Press.

Skarlicki, D. P., \& Folger, R. (1997). Retaliation in the workplace: The roles of distributive, procedural, and interactional justice. Journal of Applied Psychology, 82(3), 434. 
Snell, S. A., \& Youndt, M. A. (1995). Human-resource management and firm performance - Testing a contingency model of executive controls. Journal of Management, 21(4), 711-737.

Sobel, M. E. (1982). Asymptotic confidence intervals for indirect effects in structural equations models. In S. Leinhart (Ed.). Sociological methodology (pp. 290-312). San Francisco: Jossey-Bass.

Spector, P. E., \& Fox, S. (2002). An emotion-centered model of voluntary work behavior: Some parallels between counterproductive work behavior and organizational citizenship behavior. Human Resource Management Review, 12(2), 269-292.

Stearns, C. Z., \& Stearns, P. N. (1986). Anger: The struggle for emotional control in America's History. Chicago: University of Chicago.

Styhre, A. (2008). Management control in bureaucratic and postbureaucratic organizations a Lacanian perspective. Group \& Organization Management, 33(6), 635-656.

Tanghe, J., Wisse, B., \& van der Flier, H. (2010). The formation of group affect and team effectiveness: The moderating role of identification. British Journal of Management, $21,340-358$.

Tannenbaum, M. B., Hepler, J., Zimmerman, R. S., Saul, L., Jacobs, S., Wilson, K., et al. (2015). Appealing to fear: A meta-analysis of fear appeal effectiveness and theories. Psychological Bulletin, 141(6), 1178-1204.

Thompson, E. R. (2007). Development and validation of an internationally reliable shortform of the positive and negative affect schedule (PANAS). Journal of Cross-Cultural Psychology, 38(2), 227-242.

Thoresen, C. J., Kaplan, S. A., Barsky, A. P., Warren, C. R., \& de Chermont, K. (2003). The affective underpinnings of job perceptions and attitudes: A meta-analytic review and integration. Psychological Bulletin, 129(6), 914-945.

Van Woerkom, M., \& Meyers, M. C. (2015). My strengths count! Effects of strengths-based psychological climate on positive affect and job performance. Human Resource
Management, 54(1), 81-103

Vigoda-Gadot, E. (2007). Redrawing the boundaries of OCB? An empirical examination of compulsory extra-role behavior in the workplace. Journal of Business and Psychology, 21(3), 377-405.

Vosselman, E. G. J., \& van der Meer-Kooistra, J. (2006). Changing the boundaries of the firm - Adopting and designing efficient management control structures. Journal of Organizational Change Management, 19(3), 318-334.

Watson, D., Clark, L. A., \& Tellegen, A. (1988). Development and validation of brief measures of positive and negative affect: The PANAS scales. Journal of Personality and Social Psychology, 54(6), 1063.

Weiss, H. M., \& Cropanzano, R. (1996). Affective events theory: A theoretical discussion of the structure, causes and consequences of affective experiences at work. Research on Organizational Behavior, 18, 1-74.

Williams, L. J., \& Anderson, S. E. (1991). Job satisfaction and organizational commitment as predictors of organizational citizenship and in-role behaviors. Journal of Management, 17(3), 601-617.

Williams, S., \& Shiaw, W. T. (1999). Mood and organizational citizenship behavior: The effects of positive affect on employee organizational citizenship behavior intentions. Journal of Psychology, 133(6), 656-668.

Willmott, H. (1993). Strength is ignorance; slavery is freedom: Managing culture in modern organizations. Journal of Management Studies, 30(4), 515-552.

Wright, P. M., \& Boswell, W. R. (2002). Desegregating HRM: A review and synthesis of micro and macro human resource management research. Journal of Management, 28(3), 247-276.

Yu, B. T. W., \& Ming, T. W. (2008). Effects of control mechanisms on positive organizational change. Journal of Organizational Change Management, 21(3), 385-404. 